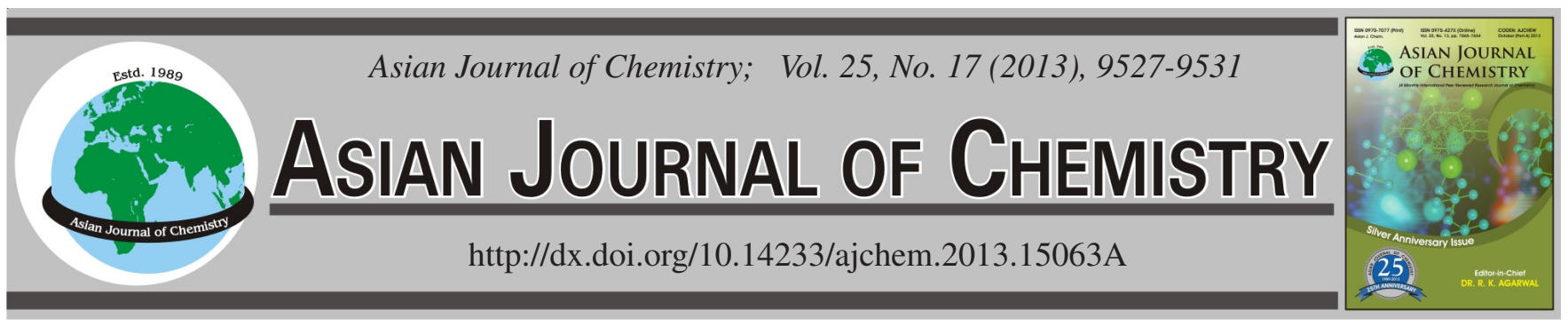

\title{
Least Squares Method to Correct the Interference of Vanadium on Aluminium Determination in Vanadium Pentoxide by Spectrophotometry with Sensitization
}

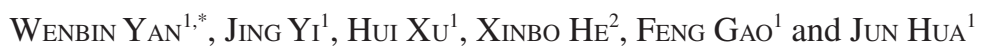

${ }^{1}$ School of Chemistry and Chemical Engineer, Jishou University, Jishou 416000, P.R. China

${ }^{2}$ School of Materials Science and Engineering, University of Science and Technology Beijing, Beijing 100083, P.R. China

*Corresponding author: E-mail: jishouyanwenbin@163.com

(Received: 31 December 2012;

Accepted: 1 October 2013)

AJC-14221

\begin{abstract}
The least square method to correction the interference of vanadium on trace amount of aluminium determination in vanadium pentoxide was studied by phenylfluorone spectrophotometry with sensitization. The sensitizing effects of various surfactants and their optimal usage conditions were examined against a blank solution at a wavelength of $560 \mathrm{~nm}$. At optimal conditions, the expression governing vanadium and aluminium's $(\mathrm{V}-\mathrm{Al})$ mixed absorbance was estimated by least squares method as: $\mathrm{A}=0.0376 \mathrm{C}_{\mathrm{Al}}+0.002902 \mathrm{C}_{\mathrm{V}}-0.0015$. The elimination method for this vanadium matrix, according to the aforementioned best-fit equation, and determined absorbance of $\mathrm{V}$-Al allowed calculation of the aluminium concentration in a solution of known vanadium concentration. The method was thus presented as able to determine the concentration of aluminium. The experimental results showed that in a $\mathrm{pH} 10$ buffer solutions, the value of $\varepsilon$ could be increased from $2.8 \times 10^{4}$ to $1.3 \times 10^{5} \mathrm{~L} \mathrm{~mol} \mathrm{~cm}^{-1}$ by Tween- $80 \AA$, the relative deviations of the calculated results and their equivalent theoretical values were within $\pm 2 \%$.
\end{abstract}

Key Words: Least squares method. Vanadium, Aluminium, Spectrophotometry.

\section{INTRODUCTION}

In recent years, vanadium pentoxide has been more widely using in the fields of aerospace, energy, paint, catalysis, luminescent materials, etc. ${ }^{1}$. However, above fields have extreme requirements of their raw materials because a raw material that contains many defect-inducing impurities affects product quality and performance ${ }^{2}$. The study of the preparation of high purity $\mathrm{V}_{2} \mathrm{O}_{5}$ is thus a current topic of interest. Meanwhile it is significant to find fast, accurate, detection methods to measure trace amount of element-particularly aluminium vanadium pentoxide.

At present, chromazurol S-tetradecyl pyridinium chloride spectrophotometry and chromazurol S spectrophotometry methods ${ }^{3,4}$ are adopted mainly for determination of aluminium content in vanadium solution although they suffer drawbacks including: tedius operation, a lack of rapidity and a need for toxic reagents. To find a better method, researchers proposed that vanadium be separated in solution by barium salt precipitation which is able to reduce the vanadium concentration to $10^{-6.6} \mathrm{mmol} / \mathrm{L}$ at $25^{\circ} \mathrm{C}^{5}$, for example, barium salt and sodium chloride were adopted by Lin Ma to separate basic vanadium and iron in the solution when Chromazurol S spectrophotometric method is used to determine aluminium content in vanadium solution ${ }^{6}$, while organic reagent extraction is not used in this method. The fast determination of aluminium in high vanadium, chromium, manganese, platinum and copper samples was carried out by Liu et al. ${ }^{7}$. And the matrix was separated using a barium chloride precipitation method as its determination process. These methods are simpler and they also avoid the use of an organic reagent compared with chromazurol S-tetradecyl pyridinium chloride spectrophotometry and chromazurol S spectrophotometry methods ${ }^{3,4}$. However, vanadium matrix separation remains unavoidable, thereby rendering the process suitable for laboratory use only.

Therefore the aim of this work is to find the most stable method for determination of trace aluminium in the vanadium solution, on the basis of no separation of the vanadium matrix, the author proposed that $\mathrm{V}-\mathrm{Al}$ mixed absorbance be measured directly by phenylfluorone spectrophotometery with Tween$80 \circledast$ sensitization, then the least squares method was used to correct the interference of vanadium on aluminium determination because of phenylfluorone having better performance and higher sensitivity compared to other reagents as a photometric analysis reagent ${ }^{8-10}$, its effects are further improved after adding surfactant ${ }^{11}$. The method proposed is not only simple and rapid, but offers good applicability. 


\section{EXPERIMENTAL}

Principal reagents: $\mathrm{NaOH}, \mathrm{HCl}, \mathrm{NH}_{4} \mathrm{Cl}, \mathrm{NH}_{3}$ aqueous solution, Tween-80, sodium tartrate, OP-emulsifier, sodium dodecyl sulphate were all analytical grade and obtained from Tianjing Guangfu Fine Chemical Co., Ltd., vanadium pentoxide and phenylfluorone (PF) were purchased from Xiangzhong Geology Institute of Hunan. $100 \mathrm{mg} / \mathrm{L}$ of aluminium stock solution were obtained from China's National Institute of Metrology.

The absorption spectrum was carried out on a $245-\mathrm{UV}$ (Shimadzu, Japan). Other experiment were carried on a 723spectrophotometer (Shanghai Mingqiao Precision Scientific Instrument Co., Ltd, China).

Method: Transfer $1 \mathrm{~mL}$ of standard reserve solution (10.0 $\mathrm{mg} / \mathrm{L}$ ) of aluminium to the $100 \mathrm{~mL}$ volumetric flask and add $1 \mathrm{~mL}$ vanadium base solution $(5 \mathrm{mg} / \mathrm{mL}), 18 \mathrm{~mL}$ sodium tartrate solution (10\%), $2 \mathrm{~mL}$ sodium tartrate solution (10\%), $1 \mathrm{~mL}$ of the $0.1 \%$ phenylfluorone solution and $40 \mathrm{~mL}$ distilled water. Heat the solution for 5 minutes at $45^{\circ} \mathrm{C}$, after cooling to room temperature; it was diluted with water to the required concentration. Then measure the absorption of the solution by a 723spectrophotometer at $560 \mathrm{~nm}$ against a blank solution.

\section{RESULTS AND DISCUSSION}

Influence of various surfactants on the absorption spectrum: Absorption spectra were determined for the various surfactants against a blank solution. Fig. 1 showed that the maximum absorption wavelength of Al-phenylfluorone only slightly changed to $577 \mathrm{~nm}$ when surfactants were added. However, the sensitivity greatly influenced the colour reaction of Al-phenylfluorone. Fig. 1 also showed that the adding an anionic surface active agent can reduce the sensitivity of the colour reaction but non-ionic surface active agents increase $\mathrm{it}^{11}$, for example, sodium dodecyl sulphate (SDS) reduces the sensitivity of any colour reaction in the experiment because of its anionic surface active nature, but the sensitivity of the colour reaction will be enhanced when adding non-ionic surface active agents, such as OP-emulsifier (OP) and Tween$80 \AA$ with Tween-80® being the highest. When $2 \mathrm{~mL}$ of $5 \%$ Tween-80® solution had been added, the value of $\varepsilon$ (the apparent molar absorption coefficient) increased from $2.8 \times$ $10^{4}-1.3 \times 10^{5} \mathrm{~L} \mathrm{~mol} \mathrm{~cm}^{-1}$ Hence, Tween-80® was chosen as the sensitisation agent for these experiments at $560 \mathrm{~nm}$.

Influence of chromogenic time and chromogenic temperature on the colour reaction: Chromogenic time and chromogenic temperature were investigated to assess their effects on the colour reaction against a blank solution. It was found during the experiments that colour reaction of Alphenylfluorone had precipitation at higher temperatures, for example, precipitates will be produced at 55,65 and $75^{\circ} \mathrm{C}$, therefore their results are not listed here. Fig. 2 showed the results from tests at room temperature and $45^{\circ} \mathrm{C}$ : the colour time was extended at low temperatures, i.e., the chromogenic time was over within $1 \mathrm{~h}$ at room temperature, by contrast only 5 min was requested at $45^{\circ} \mathrm{C}$ and its value of absorbance was unchanged in $2 \mathrm{~h}$. Therefore, it was beneficial to the colour reaction when the temperature was increased without precipitates

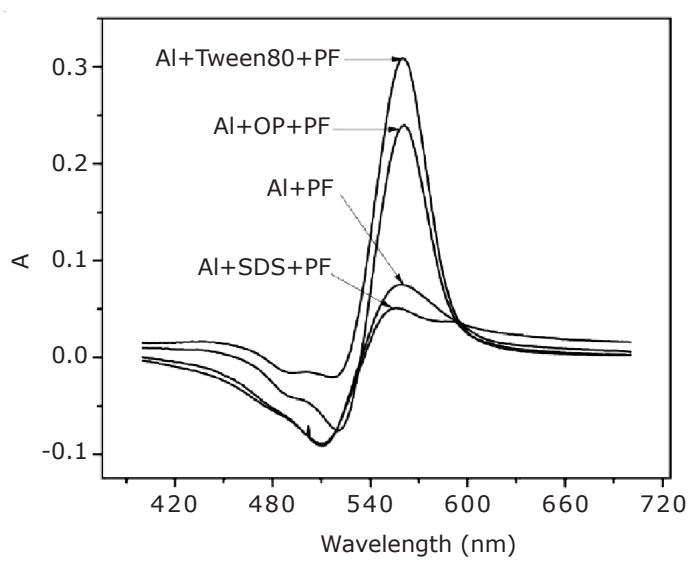

Fig. 1. Influence of various surfactants on the absorption spectra

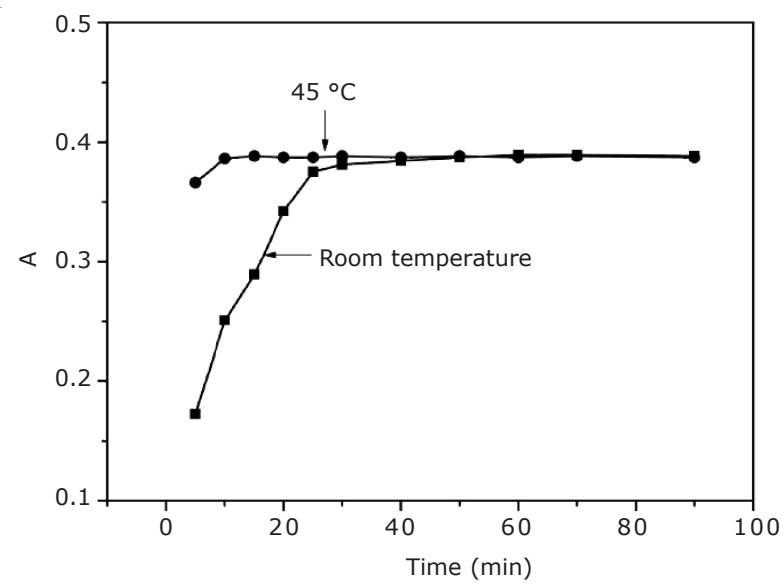

Fig. 2. Influence of chromogenic time at different temperatures on the colour reaction

being produced. Thus, $45^{\circ} \mathrm{C}$ was chosen as the chromogenic temperature and $5 \mathrm{~min}$ as the chromogenic time.

Influence of buffer solution dosage on the chromogenic reaction: Interference of determination was decreased because of most of the metal ions formed precipitates in the weak alkali conditions. The research reported that phenylfluorone has better colour effect in the $\mathrm{pH} 10$ buffer solution ${ }^{12}$, therefore phenylfluorone is chosen for this experiment. Its dosage was investigated to assess its effects on the colour reaction against a blank solution. The result as shown in Fig. 3, with increased buffer solution content, the value of absorbance first increased, then decreased, with its absorbance basically unchanged when the buffer solution dosage increased from 12 to $20 \mathrm{~mL}$. Therefore, $18 \mathrm{~mL}$ of buffer solution was chosen for these experiments.

Influence of phenylfluorone dosage on the chromogenic reaction: Chromogenic agents greatly influence to the value of absorbance in the colour reaction, such when the amount of chromogenic agents added was not enough, the complexation reaction will not carried out completely so that the value of absorbance declined. Also, the absorbance value will be changed with the increase of chromogenic agents dose because of its own colour, to eliminate this influence, these experiments set a reagent blank as their reference and phenylfluorone dosage was investigated for its effect on the colour reaction. Fig. 4 apparently indicates that the absorbance value remained 


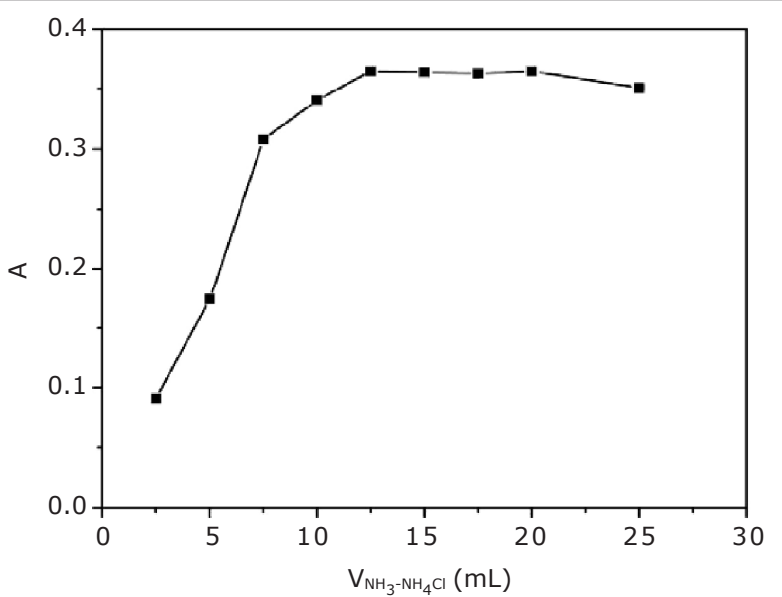

Fig. 3. Influence of buffer solution dosage on the chromogenic reaction

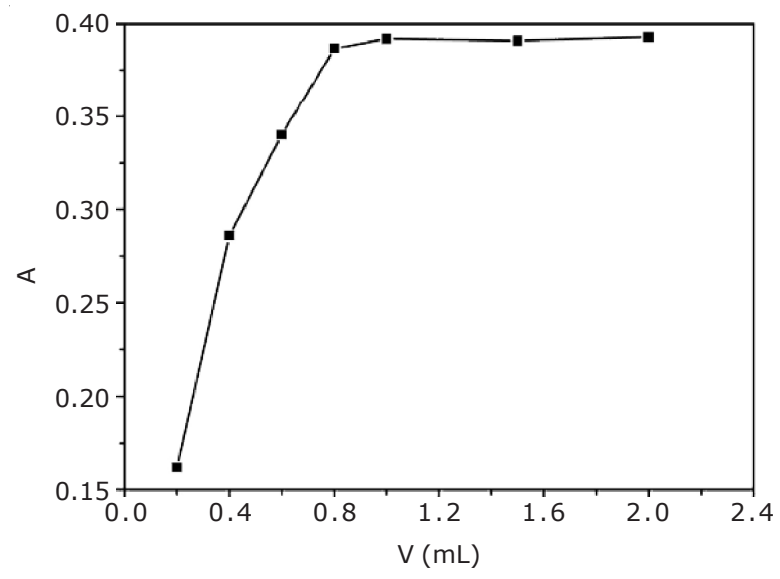

Fig. 4. Influence of PF dosage on the chromogenic reaction

unchanged for phenylfluorone dosages above $0.8 \mathrm{~mL}$. Therefore, $1 \mathrm{~mL}$ of phenylfluorone was chosen for these experiments.

Influence of Tween ${ }^{\circledR}$ dosage on the chromogenic reaction: This was difficult to complete in water because the sensitivity and selectivity were insufficient and non-ideal for this colour reaction of the phenyl fluorescence ketone reagent and and metal ions without surfactants. Surfactant was added to improve the analysis performance of the reagent and with reference to Fig. 1 shows that surfactant exerted a significant influence on the reaction sensitivity. To explore the influence of surfactant dosage, the amount of Tween- $80 \AA$ was investigated with regard to its effect on the colour reaction. It is evident from Fig. 5 that absorbance value first increased, then decreased with a rise in the Tween- $80 \AA$ dosage. Absorbance value basically remained unchanged and reached its maximum at Tween- $80 ®$ dosages of between 1.5-2.0 mL. Therefore, $1.5 \mathrm{~mL}$ of Tween$80 \AA$ dosage was chosen for these experiments.

Influence of sodium tartrate dosage on the chromogenic reaction and elimination of Fe interference: Iron is the main interference element except the vanadium matrix interference for determination of aluminium in the vanadium pentoxide; because phenylfluorone and many metal ions can produce the colour reaction arise. According to the literature ${ }^{13}$, it can be eliminated through addition of an appropriate amount of sodium tartrate and thus sodium tartrate dosage was investigated with

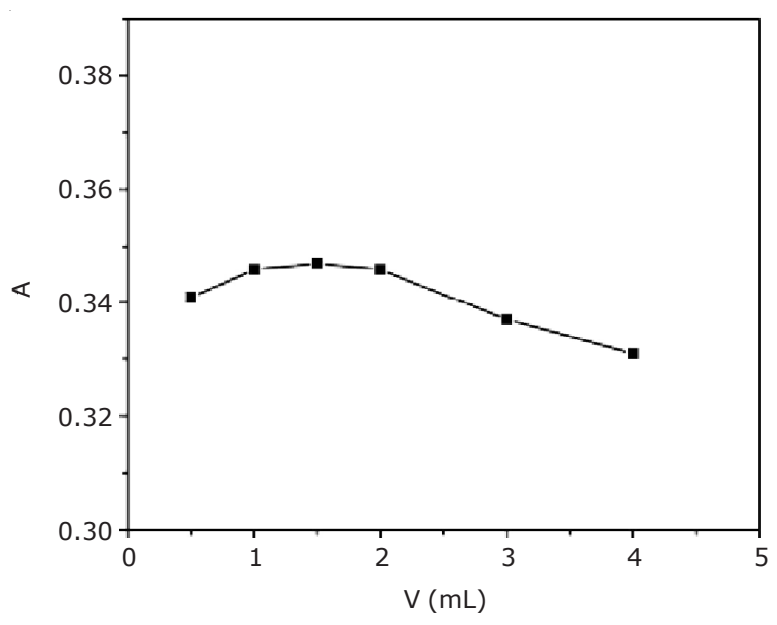

Fig. 5. Influence of Tween- $80 ®$ dosage on the chromogenic reaction

regard to its effect on the colour reaction compared against a blank solution. It is evident from Fig. 6 that the sodium tartrate dosage did not affect the colour reaction at quantities below $3 \mathrm{~mL}$, so $2 \mathrm{~mL}$ of sodium tartrate was chosen for these experiments. Study of which amount of added iron did not affect the colour reaction $0.20 \mu \mathrm{g} / \mathrm{mL}$; iron interference could be completely eliminated to the aluminium concentration determination in these samples of high vanadium pentoxide.

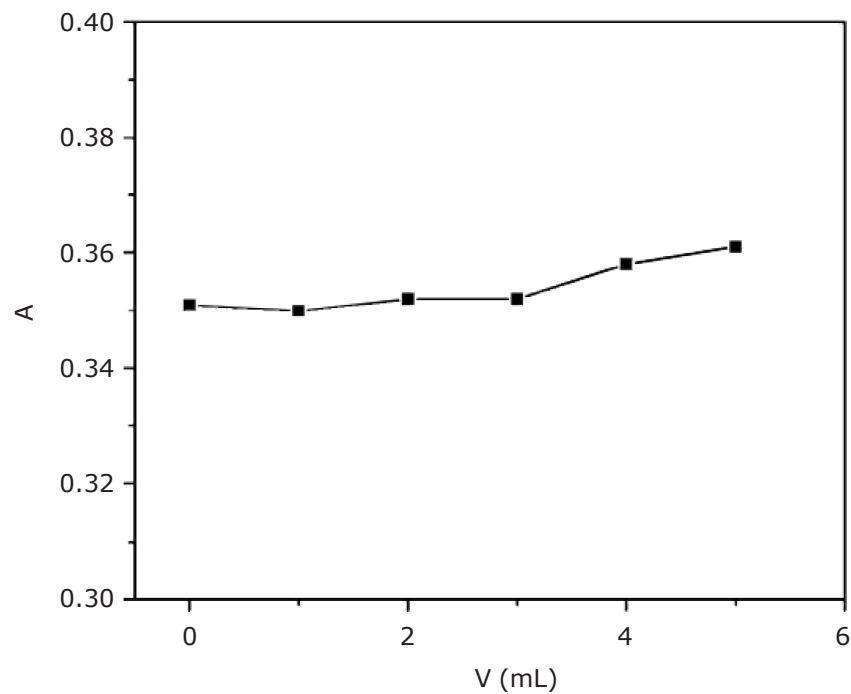

Fig. 6. Influence of sodium tartrate dosage on the chromogenic reaction

\section{Building of vanadium matrix interference mathematical} model: the effect of aluminium

Different aluminium concentration absorption curves: When a large number of vanadium matrix is found, whether the reaction of aluminium and chromogenic agents fits Beer's law or not was investigated through changed aluminium concentration. Fig. 7 shows that light absorption properties at $560 \mathrm{~nm}$ for reaction of aluminium and chromogenic agents fit Beer's law, the linear equation is fitted as:

$$
y=0.0379 x+0.0049
$$

with $\mathrm{R}=0.9993$ within the limits of an aluminium concentration of $0-25 \mu \mathrm{g} / 100 \mathrm{~mL}$. 


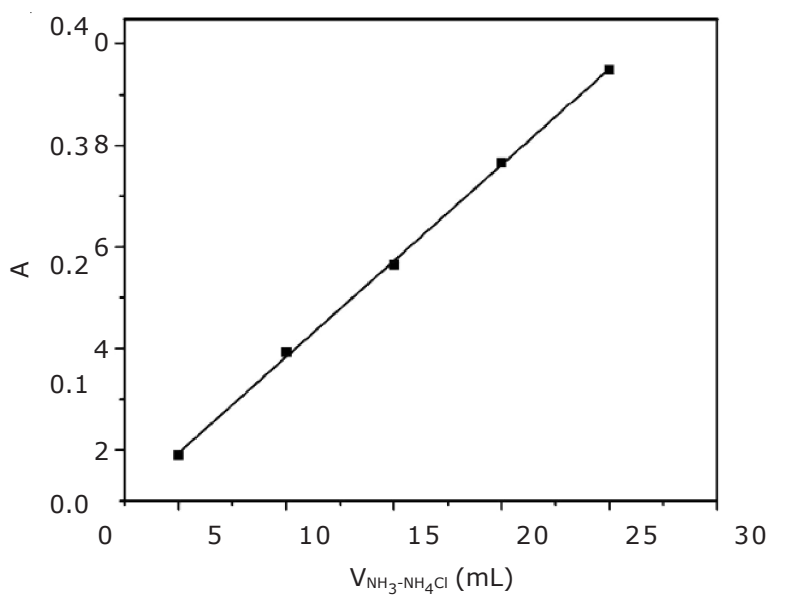

Fig. 7. Effect ot difterent alumınıum concentratıons on the absorption curve at $560 \mathrm{~nm}$

Interference of different vanadium to aluminium determination: Interference of vanadium to aluminium determination was mainly depended on two aspects as follow: whether vanadium and phenylfluorone can produce colour reaction or not, what is the change of colour reaction like if the said colour reaction was produced? Meanwhile, what is the impact of vanadium with different concentration on the reaction of aluminium and phenylfluorone? Therefore, it was investigated through changed aluminium concentration and vanadium concentration. Fig. 8 indicates that the absorption curve of aluminium at $560 \mathrm{~nm}$ shifted upwards with the increase of vanadium concentration and in this up-shifting process, the multiple by which the vanadium concentration increased was equal thereto: the linearity of the aluminium absorption curve was not affected by vanadium concentration, meanwhile, light absorption properties fitted Beer's law for reaction of vanadium and chromogenic agents at $560 \mathrm{~nm}$. So it can be concluded that the value of mixed $\mathrm{V}-\mathrm{Al}$ absorbance should be co-planar with best-fit equation:

$$
\mathrm{A}=\mathrm{aC}_{\mathrm{Al}}+\mathrm{bC}_{\mathrm{V}}+\mathrm{c}
$$

here: $\mathrm{A}$ is the value of mixed $\mathrm{V}-\mathrm{Al}$ absorbance, $\mathrm{a}, \mathrm{b}$ and $\mathrm{c}$ are constants, $\mathrm{C}_{\mathrm{Al}}$ is the aluminium concentration of the solution and $\mathrm{C}_{\mathrm{V}}$ is the vanadium concentration thereof (as measured by $\mathrm{V}_{2} \mathrm{O}_{5}$ meter).

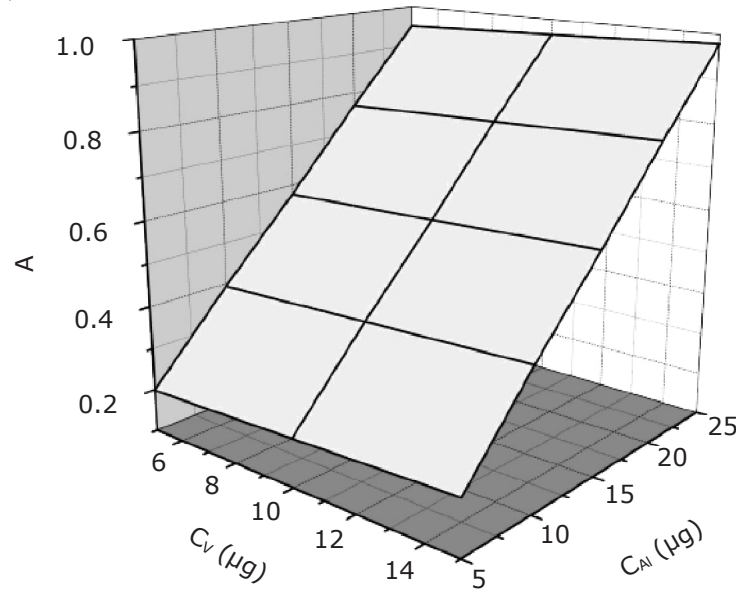

Fig. 8. 3-D graph of different V-Al mixed absorbance value
Least squares fit mathematical model: interference of vanadium with aluminium: From the above discussions, it was found that for different vanadium and aluminium concentrations that data point $\left(\mathrm{x}_{\mathrm{i}}, \mathrm{y}_{\mathrm{i}}, \mathrm{z}_{\mathrm{i}}\right), \mathrm{i}=1,2,3,4, \ldots, \mathrm{N}=15$, which provided a best-fit to the model's plane equation: $\mathrm{A}=$ $\mathrm{aC}_{\mathrm{Al}}+\mathrm{bC}_{\mathrm{V}}+\mathrm{c}$, according to the least squares principle ${ }^{14}$, then the total error may be represented as follows:

$$
\mathrm{Q}(\mathrm{a}, \mathrm{b}, \mathrm{c})=\sum_{\mathrm{i}=1}^{\mathrm{n}}\left[\mathrm{A}_{\mathrm{i}}-\left(\mathrm{aC}_{\mathrm{Al}_{\mathrm{i}}}+\mathrm{bC}_{\mathrm{V}_{\mathrm{i}}}+\mathrm{c}\right)\right]^{2}=\min
$$

According to the fundamental theorem of calculus, the solutions were attributed to solve extreme value of ternary function $\mathrm{Q}(\mathrm{a}, \mathrm{b}, \mathrm{c})$, i.e., $\mathrm{a}, \mathrm{b}$ and $\mathrm{c}$ should satisfy the equation as follow:

$$
\frac{\partial \mathrm{Q}}{\partial \mathrm{a}}=0, \frac{\partial \mathrm{Q}}{\partial \mathrm{b}}=0, \frac{\partial \mathrm{Q}}{\partial \mathrm{c}}=0
$$

The equation of ternary function $\mathrm{Q}$ is:

$$
\mathrm{Q}(\mathrm{a}, \mathrm{b}, \mathrm{c})=2 \sum_{\mathrm{i}=1}^{0}\left[\mathrm{~A}_{\mathrm{i}}-\left(\mathrm{aC}_{\mathrm{Al}_{\mathrm{i}}}+\mathrm{bC}_{\mathrm{V}_{\mathrm{i}}}+\mathrm{c}\right)\right]\left(-\mathrm{C}_{\mathrm{Al}_{\mathrm{i}}}\right)=0 \text { (4) }
$$

That is to say:

$$
\mathrm{a} \sum_{\mathrm{i}=1}^{\mathrm{n}} \mathrm{C}_{\mathrm{Al}_{\mathrm{i}}^{2}}+\mathrm{b} \sum_{\mathrm{i}=1}^{\mathrm{n}} \mathrm{C}_{\mathrm{Al}_{\mathrm{i}}} \mathrm{C}_{\mathrm{V}_{\mathrm{i}}}+\mathrm{c} \sum_{\mathrm{i}=1}^{\mathrm{n}} \mathrm{C}_{\mathrm{Al}_{\mathrm{i}}}=\sum_{\mathrm{i}=1}^{\mathrm{n}} \mathrm{C}_{\mathrm{Al}_{\mathrm{i}}} \mathrm{A}_{\mathrm{i}}
$$
follows:

By the same measure two equations may be obtained as

$$
\begin{gathered}
\mathrm{a} \sum_{\mathrm{i}=1}^{\mathrm{n}} \mathrm{C}_{\mathrm{Al}_{\mathrm{i}}} \mathrm{C}_{\mathrm{V}_{\mathrm{i}}}+\mathrm{b} \sum_{\mathrm{i}=1}^{\mathrm{n}} \mathrm{C}_{\mathrm{V}_{\mathrm{i}}^{2}}+\mathrm{c} \sum_{\mathrm{i}=1}^{\mathrm{n}} \mathrm{C}_{\mathrm{V}_{\mathrm{i}}}=\sum_{\mathrm{i}=1}^{\mathrm{n}} \mathrm{C}_{\mathrm{V}_{\mathrm{i}}} \mathrm{A}_{\mathrm{i}} \\
\mathrm{a} \sum_{\mathrm{i}=1}^{\mathrm{n}} \mathrm{C}_{\mathrm{Al}_{\mathrm{i}}}+\mathrm{b} \sum_{\mathrm{i}=1}^{\mathrm{n}} \mathrm{C}_{\mathrm{V}_{\mathrm{i}}}+\mathrm{cN}=\sum_{\mathrm{i}=1}^{\mathrm{n}} \mathrm{A}_{\mathrm{i}}
\end{gathered}
$$

According to Table-1's data, eqns. 5-7 are written as follows:

$$
\begin{gathered}
4125 a+2250 b+225 c=161.26 \\
2250 a+1750 b+150 c=89.455 \\
225 a+150 b+15 c=8.873
\end{gathered}
$$

Thus: $\mathrm{a}=0.0376, \mathrm{~b}=0.002902$ and $\mathrm{c}=-0.0015$. The expression of mixed $\mathrm{V}-\mathrm{Al}$ absorbance measurement value is written as follows: $\mathrm{A}=0.0376 \mathrm{C}_{\mathrm{Al}}+0.002902 \mathrm{C}_{\mathrm{V}}-0.0015$, from which the aluminium ion concentration whose mixed absorbance was determined from the mixed V-Al solution of known vanadium concentration is found.

Mathematical modelling of aluminium concentration in the mixed solution of standard vanadium and aluminium: Mixed absorbance solutions were tested in a series with a certain amount of mixed $\mathrm{V}$-Al solution against reagents blank and results are listed in Table-1. It can be seen from Table-1 that calculated values of the aluminium concentration were close to standard values, from which the maximum relative deviation was $1.87 \%$. The relative deviation of all results was less than $\pm 2 \%$. These results potentially demonstrated the method's accuracy, reliability and ability to meet the test requirements. 


\begin{tabular}{|c|c|c|c|c|c|c|c|c|}
\hline \multicolumn{9}{|c|}{$\begin{array}{c}\text { TABLE-1 } \\
\text { RELATIONSHIP CONVERSION IN DIFFERENT VANA }\end{array}$} \\
\hline & $\mathrm{Cu}$ & $\mathrm{C}_{\mathrm{V}}$ & A & $\mathrm{C}_{\mathrm{Al}}{ }^{2}$ & $\mathrm{C}_{\mathrm{V}}{ }^{2}$ & $\mathrm{C}_{\mathrm{Al}} \times \mathrm{C}_{\mathrm{V}}$ & $\mathrm{C}_{\mathrm{Al}} \times \mathrm{A}$ & $\mathrm{C}_{\mathrm{A}} \times \mathrm{A}$ \\
\hline 1 & 5 & 5 & 0.199 & 25 & 25 & 25 & 0.995 & 0.995 \\
\hline 2 & 10 & 5 & 0.393 & 100 & 25 & 50 & 3.93 & 1.965 \\
\hline 3 & 15 & 5 & 0.576 & 225 & 25 & 75 & 8.64 & 2.88 \\
\hline 4 & 20 & 5 & 0.768 & 400 & 25 & 100 & 15.36 & 3.84 \\
\hline 5 & 25 & 5 & 0.95 & 625 & 25 & 125 & 23.75 & 4.75 \\
\hline 6 & 5 & 10 & 0.212 & 25 & 100 & 50 & 1.06 & 2.12 \\
\hline 7 & 10 & 10 & 0.408 & 100 & 100 & 100 & 4.08 & 4.08 \\
\hline 8 & 15 & 10 & 0.59 & 225 & 100 & 150 & 8.85 & 5.9 \\
\hline 9 & 20 & 10 & 0.782 & 400 & 100 & 200 & 15.64 & 7.82 \\
\hline 10 & 25 & 10 & 0.964 & 625 & 100 & 250 & 24.1 & 9.64 \\
\hline 11 & 5 & 15 & 0.227 & 25 & 225 & 75 & 1.135 & 3.405 \\
\hline 12 & 10 & 15 & 0.423 & 100 & 225 & 150 & 4.23 & 6.345 \\
\hline 13 & 15 & 15 & 0.605 & 225 & 225 & 225 & 9.075 & 9.075 \\
\hline 14 & 20 & 15 & 0.797 & 400 & 225 & 300 & 15.94 & 11.955 \\
\hline 15 & 25 & 15 & 0.979 & 625 & 225 & 375 & 24.475 & 14.685 \\
\hline$\Sigma$ & 225 & 150 & 8.873 & 4125 & 1750 & 2250 & 161.26 & 89.455 \\
\hline
\end{tabular}

\begin{tabular}{cccc}
\multicolumn{5}{c}{ TABLE-2 } \\
\multicolumn{4}{c}{ ANALYTICAL RESULTS SHOWING CALCULATED } \\
ALUMINIUM IN STANDARD V-Al MIXED SOLUTION \\
\hline $\begin{array}{c}\text { Added } \\
\text { aluminum }(\mu \mathrm{g})\end{array}$ & $\begin{array}{c}\text { Added } \\
\text { vanadium }(\mathrm{mg})\end{array}$ & $\begin{array}{c}\text { Calculated } \\
\text { aluminum }(\mu \mathrm{g})\end{array}$ & $\begin{array}{c}\text { Relative } \\
\text { deviation }(\%)\end{array}$ \\
\hline 5 & 5 & 5.08 & 1.59 \\
5 & 10 & 4.91 & -1.87 \\
5 & 15 & 5.03 & 0.52 \\
10 & 5 & 10.11 & 1.06 \\
10 & 10 & 9.91 & -0.94 \\
10 & 15 & 10.08 & 0.79 \\
20 & 5 & 20.16 & 0.8 \\
20 & 10 & 20.17 & 0.86 \\
20 & 15 & 19.97 & -0.14 \\
\hline
\end{tabular}

\section{Conclusion}

It is practically important to measure trace aluminium and finding a simple, rapid method which does not suffer interference with vanadium matrix elements in the vanadium pentoxide preparation process, is critical. Phenylfluorone spectrophotometry was used to determine trace aluminium levels in vanadium pentoxide samples. It was found that Tween- $80 \AA$ was able to offer the best effect as a sensitization agent through its sensitization of the surfactant in the tests. Meanwhile interference from iron can be eliminated by the addition of an appropriate sodium tartrate solution. For the method's elimination of vanadium matrix effects, a plane simulation equation was presented to experimentally calibrate the level of aluminium under optimal test conditions. According to the calculated results, after calibration, the relative deviation was less than $\pm 2 \%$, thereby rendering the calculated values of aluminium concentration close to standard values. This implied that the method was feasible. From experiments it was apparent that the principle and calculation was simple for this method once the basic simulation equation had been confirmed. The method can be used for samples measured over lengthy times as long as the instruments were sufficiently stable, accurate and reliable. Compared with reported results, the method has advantages of simple, quick, accurate, reliable, with opportunities arising for its application in both laboratory and industrial environments.

\section{ACKNOWLEDGEMENTS}

This work was financially supported by National Key Science-Technology Support Plan Projects of China (No. 2012BAE06B04).

\section{REFERENCES}

1. Z. Wang and J. Wang, Mining Metallurgy (China), 16, 47 (2007).

2. W.J. Huang, L.C. Dou and Y.Q. Wang, China Patent, 10155853 (2008).

3. GB/T8704.8-20098704.8, Determination of Aluminium in Vanadium by Chromazurol S-Tetradecyl Pyridinium Chloride Spectrophotometry, Chinese Industrial Standards Committee, China (2009).

4. GB 8639.3, Determination of Aluminium in Vanadium-Iron by Chromazurol S Spectrophotometry Methods, Chinese Industrial Standards Committee, China (1988)

5. Y. Cheng, Solution Chemistry \& Separation Technology of Aluminum, Vanadium and Molybdenum in Alkaline Solution, ed. D. Central South University, China (2006).

6. L. Ma, Public Commun. Sci. Technol. (China), 7, 113 (2011).

7. G.Z. Liu, J.K. Geng and B.H. Leng, Metallurgical Anal., 5, 23 (1982).

8. A.K. Malik, J. Kapo and A.L.J. Rao, J. Environ. Monit., 2, 367 (2000).

9. V.G. Amelin and O.I. Abramenkova, J. Anal. Chem., 63, 1112 (2008).

10. W. Winkler, F. Buhl, A.A. vel Pacula and U. Hachula, Anal. Bioanal. Chem., 376, 934 (2003).

11. G.C. Fang, X. Zhou and H.S. Zhang, Metallurgical Anal. (China), 18, 1 (1995).

12. Y.M. Xu and Y.H. Chen, J. Nanchang Univ. (Nat. Sci.) (China), 25, 72 (2001).

13. R.S. Du, Y. Gu and G.F. Luo, Chin. J. Anal. Lab., 28S 157 (2009).

14. L.Q. Zhou, Sci. Technol. Inform., 23, 282 (2010). 